\title{
Mortality from lung cancer among copper miners
}

\author{
Ruoling Chen, Li Wei, Huaming Huang
}

\begin{abstract}
A cohort mortality study of lung cancer in 7088 copper miners was made from 1 January 1969 to 31 December 1988. There was an excess of deaths from lung cancer in the copper miners. The standardised mortality ratio (SMR) was $147(p<0.01)$. The SMR increased with calendar period. There was a higher risk of deaths from lung cancer in the miners employed in the 1950s. Age at the start of exposure had no effect on the risk of lung cancer. The risk of death from lung cancer increased with the duration of exposure and the time since first exposure. The SMR for lung cancer was 173 in underground miners and 193 for drilling miners (both $p<0.01$ ). These data show that exposure to dust is associated with an excess of deaths from lung cancer in copper miners whereas exposure to radiation does not seem to carry such risk.
\end{abstract}

(British Fournal of Industrial Medicine 1993;50:505-509)

It is well known that there is a high risk of lung cancer in iron, tin, and uranium miners. ${ }^{1-6}$ Little is known, however, about mortality from lung cancer in copper miners. Recently, we showed that the risks of death from lung cancer and stomach cancer were increased in copper miners. ${ }^{7}$ Ahlman et al ${ }^{8}$ also suggested a higher mortality from lung cancer in copper miners as part of their report on the mortality of sulphide ore miners. In this study we investigated in detail the risk of death from lung cancer in copper miners by evaluation of a historical

Department of Biostatistics, Anhui Medical University, Hefei, Anhui, The People's Republic of China

R L Chen, Li Wei

Chaire de Médecine Expérimentale, Collège de France, 3, rue d'Ulm, 75005, Paris, France H Huang

INSERM U263 et URBB, Université Paris VII, Tour 53, 2, Place Jussieu, 75005, Paris, France

$\mathrm{R}$ L Chen cohort at Tongling copper mine in the Anhui province of China from 1 January 1969 to 31 December 1988.

\section{Materials and methods \\ THE MINE}

The copper mine, which is situated at Tongling city in the Anhui province of China, is one of the largest and oldest copper mines in China. It has a hundred years of developed history, but it was increased on a large scale only after 1950 . Tongling city has experienced considerable growth since large scale development of the copper mine began and now copper miners account for $15 \%$ of the population of Tongling city. In Chinese, "Tong" means copper, and "Ling" means mountains. The major product of the mine is copper ore. In drilling and transporting this ore, the miners are exposed to ore dust and possible radioactivity. The amount of dust measured from 1963 to 1988 was in the range of 4-10 $\mathrm{mg} / \mathrm{m}^{3} .{ }^{9} \mathrm{~A}$ higher concentration of the dust before 1963 is likely because a dry drilling method was used and underground ventilation was not yet improved. Radioactivity in the mine, measured between 1960 to 1990 , showed concentrations of radioactivity from radon and daughters in the mine of $1.29\left(\mathrm{SD} \mathrm{0.55)} \times 10^{-11} \mathrm{Ci} / 1\right.$ (unpublished data).

\section{SUBJECTS}

Our study was carried out from 1985 to 1988 . The population consisted of all male workers in the mine who had worked for at least one year between 1 January 1969 and 31 December 1988, a total of 7088 subjects. Women were excluded because there were too few to make an analysis feasible. We obtained the occupational recording cards and certification of deaths, which were kept entirely at the mine because they were needed to obtain worker's benefits. Information on each subject of the cohort was abstracted from the card, including his name, birth date, dates of starting and leaving employment, and descriptions and times of all jobs undertaken. The job titles taken from the personnel occupational card have been grouped according to the type of work undertaken in the mine. A classification of exposure was derived for these miners 
according to their sections and jobs. They were divided into three categories: (1) all minersincluding underground and other miners; (2) underground miners-miners who had worked underground for at least one year; (3) drilling miners-only those who had worked at drilling for at least one year.

All certifications of deaths were checked in the hospitals of Tongling. Diagnosis of lung cancer was based on $x$ ray film or $x$ ray film plus histopathological examination.

\section{STATISTICAL ANALYSIS}

The causes of death have been classified according to the ninth revision of the International Classification of Diseases. Computation of personyears at risk was obtained with a computer program we had developed previously. ${ }^{10}$ The expected number of deaths was calculated on the basis of male specific mortality in 1985 for each of the five age groups in Tongling city. The mortality risk for the copper miners was expressed as the standardised mortality ratio (SMR), the observed/expected number of deaths. The statistical significance of the SMR was tested and $95 \%$ confidence intervals of the SMRs were calculated assuming a Poisson distribution. ${ }^{11}$

Table 1 Follow up status of study cohort on 31 December 1988

\begin{tabular}{lll}
\hline Status & Number & $(\%)$ \\
\hline Known to be living & 5920 & $(83.52)$ \\
Known to be deceased & 814 & $(11 \cdot 48)$ \\
Status unknown & 354 & $(4.99)$ \\
Total & 7088 & $100 \cdot 00$ \\
\hline
\end{tabular}

\section{Results}

From a total of 7088 miners, 354 persons could not be traced for vital status, giving an overall follow up rate of $95.01 \%$. Table 1 lists the vital status of subjects in the cohort. There were 98743 person-years in the study cohort. Of these, 2962 person-years were lost. A follow up rate of $97 \cdot 00 \%$ was calculated according to the method of maximum personyears. A total of 814 deaths was observed, which was significantly greater than the expected number (545). Table 2 describes the different causes of death. Overall cancer mortality was increased and accounted for $34.15 \%$ of the total deaths (first rank of total deaths). Sixty miners had died of lung cancer compared with 40.75 expected, the SMR of which $(=147)$ was the highest among all sites of cancer.

The observed and expected number were calculated according to the year and age of deaths from lung cancer (table 3). The SMR tended to increase with age and was significant at 60 years of age $(p<$ $0 \cdot 01$ ). Table 4 shows deaths from lung cancer and SMR in relation to years exposed and age of starting exposure. There was a higher risk of deaths from lung cancer among the miners employed in the 1950 s $(S M R=157, p<0.05)$. Age at the start of exposure had no effect on risk: the SMRs were 91,156 , and 156 for the 18-25 year, 25-35 year, and $35-45$ year groups respectively. Table 5 further describes the SMR of lung cancer relative to the duration of exposure and the time since first exposure. The SMR was found to increase with both the duration of exposure and the time since first exposure.

Whereas the analyses described were on the group of all miners, the SMR for lung cancer was further examined in each of three different categories of exposure, all miners, underground miners and drilling miners. Whereas the SMR for all sites of cancer.was the same among the categories, it was not so for lung cancer. Excess for lung cancer was more pronounced among underground miners

Table 2 Observed and expected deaths and SMR in the copper miners

\begin{tabular}{|c|c|c|c|c|}
\hline Cause of death $(I C D-9)$ & Observed deaths & Expected deaths & $S M R$ & $95 \% C I$ \\
\hline All causes of death & 814 & $545 \cdot 00$ & $149^{\star \star}$ & $139-160$ \\
\hline Pulmonary tuberculosis (11) & 29 & $24 \cdot 40$ & 119 & $81-171$ \\
\hline All sites cancer $(140-208)$ & 278 & $225 \cdot 16$ & $123^{\star \star}$ & $109-139$ \\
\hline Oesophagus $(150)$ & 50 & $38 \cdot 24$ & 131 & $97-172$ \\
\hline Stomach $(151)$ & 90 & $68 \cdot 82$ & $131^{\star}$ & $105-161$ \\
\hline Liver (155) & 44 & $41 \cdot 85$ & 105 & $76-142$ \\
\hline Lung (162) & 60 & 40.75 & $147^{\star \star}$ & $112-189$ \\
\hline Disease of the circulatory system $(390-459)$ & 142 & $187 \cdot 37$ & $76^{\star \star}$ & $63-89$ \\
\hline Hypertensive disease $(401-405)$ & 20 & $9 \cdot 13$ & $219^{\star \star}$ & $136-339$ \\
\hline Cerebrovascular disease $(430-438)$ & 80 & $104 \cdot 19$ & $77^{\star}$ & $61-96$ \\
\hline Disease of respiratory system $(460-519)$ & 165 & $52 \cdot 00$ & $317 \star \star$ & $191-369$ \\
\hline Silicosis & 121 & $10 \cdot 10$ & $1198^{\star \star}$ & $994-1432$ \\
\hline Disease of digestive system (520-579) & 23 & $28 \cdot 03$ & 82 & $51-123$ \\
\hline Cirrhosis of liver (571) & 15 & 13.98 & 107 & $60-177$ \\
\hline Industrial injury (800-959) & 76 & $23 \cdot 20$ & $328^{\star \star}$ & $258-410$ \\
\hline Accident injury (E 800-E 900) & 42 & $42 \cdot 46$ & 99 & $71-134$ \\
\hline
\end{tabular}


Table 3 Observed and expected number of lung cancer deaths in the copper miners by year and age at death

\begin{tabular}{|c|c|c|c|c|c|c|}
\hline \multirow[b]{2}{*}{ Age (y) at death } & \multicolumn{6}{|c|}{ Year of death } \\
\hline & $\begin{array}{l}1970- \\
\text { Obs (exp) }\end{array}$ & $\begin{array}{l}1975- \\
\text { Obs (exp) }\end{array}$ & $\begin{array}{l}1980- \\
\text { Obs (exp) }\end{array}$ & $\begin{array}{l}1985-1988 \\
\text { Obs (exp) }\end{array}$ & $\begin{array}{l}\text { Total } \\
\text { Obs }(\exp )\end{array}$ & $O b s(\exp )$ \\
\hline $\begin{array}{l}18-44 \\
45- \\
50- \\
55- \\
60- \\
65- \\
70-80\end{array}$ & $\begin{array}{l}0(0.72) \\
0(0.89) \\
1(0.85) \\
1(1.22) \\
1(0.55) \\
0(0.15) \\
1(0.05)\end{array}$ & $\begin{array}{l}1(0.66) \\
1(1.10) \\
1(1.49) \\
3(2.94) \\
2(1.51) \\
2(0.43) \\
1(0.45)\end{array}$ & $\begin{array}{r}0(0.67) \\
1(0.89) \\
2(1.67) \\
10(4.76) \\
10(3.34) \\
0(1.12) \\
0(1.28)\end{array}$ & $\begin{array}{l}0(0.54) \\
0(0.63) \\
2(1.17) \\
5(4.62) \\
8(3.60) \\
5(1.49) \\
2(1.96)\end{array}$ & $\begin{array}{c}1(2.59) \\
2(3.51) \\
6(5.18) \\
19(13.54) \\
21(9.00) \\
7(3.19) \\
4(3.74)\end{array}$ & $\begin{array}{l}39 \\
57 \\
116 \\
140 \\
233^{\star \star} \\
219 \\
107\end{array}$ \\
\hline $\begin{array}{l}\text { Total } \\
\text { SMR }\end{array}$ & $90^{4(4 \cdot 43)}$ & $11(8 \cdot 58)$ & $\underset{168^{\star}}{23(13 \cdot 73)}$ & $\frac{22(14 \cdot 01)}{157^{\star}}$ & $60(40 \cdot 75)$ & $147^{\star \star}$ \\
\hline
\end{tabular}

${ }^{\star} \mathrm{p}<0.05 ;{ }^{\star \star} \mathrm{p}<0.01$.

Table 4 Observed and expected number of lung cancer deaths in the copper miners by year and age at start of exposure

\begin{tabular}{|c|c|c|c|c|c|c|c|c|}
\hline \multirow[b]{2}{*}{$\begin{array}{l}\text { Age }(y) \text { at } \\
\text { start of exposure }\end{array}$} & \multicolumn{8}{|c|}{ Year of stan of exposure } \\
\hline & $\begin{array}{l}1950 \\
\text { Obs (exp) }\end{array}$ & $S M R$ & $\begin{array}{l}1960- \\
\text { Obs }(\exp )\end{array}$ & $S M R$ & $\begin{array}{l}1970-88 \\
\text { Obs }(\exp )\end{array}$ & SMR & $\begin{array}{l}\text { Total } \\
\text { Obs }(\exp )\end{array}$ & $S M R$ \\
\hline $\begin{array}{l}18- \\
25- \\
35-45\end{array}$ & $\begin{array}{rr}5 & (4 \cdot 42) \\
30 & (19 \cdot 13) \\
21 & (12 \cdot 20)\end{array}$ & $\begin{array}{l}113 \\
157^{\star} \\
172\end{array}$ & $\begin{array}{l}0(0.34) \\
2(1 \cdot 10) \\
2(2.09)\end{array}$ & $\begin{array}{r}0 \\
182 \\
96\end{array}$ & $\begin{array}{l}0(0.75) \\
0(0.23) \\
0(0.48)\end{array}$ & $\begin{array}{l}0 \\
0 \\
0\end{array}$ & $\begin{array}{r}5(5 \cdot 51) \\
32(20 \cdot 46) \\
23(14 \cdot 77)\end{array}$ & $\begin{array}{c}91 \\
156^{\star} \\
156^{\star}\end{array}$ \\
\hline Total & $56(35 \cdot 75)$ & $157^{\star}$ & $4(3.53)$ & 113 & $0(1 \cdot 46)$ & 0 & $60(40 \cdot 74)$ & $147^{\star}$ \\
\hline
\end{tabular}

${ }^{\star} \mathrm{p}<0.05$.

Table 5 Lung cancer deaths by the duration of exposure and the time since first exposure in the copper miners

\begin{tabular}{|c|c|c|c|c|c|c|c|c|c|}
\hline \multirow[b]{2}{*}{$\begin{array}{l}\text { Duration of } \\
\text { exposure }(y)\end{array}$} & \multicolumn{9}{|c|}{ Time since first exposure $(y)$} \\
\hline & $\begin{array}{l}<10 \\
\text { Obs }(\exp p\end{array}$ & $\begin{array}{l}10 \\
\text { Obs }(\exp )\end{array}$ & $\begin{array}{l}15- \\
\text { Obs }(\exp )\end{array}$ & $\begin{array}{l}20- \\
O b s(e x p)\end{array}$ & $\begin{array}{l}25- \\
O b s(\exp )\end{array}$ & $\begin{array}{l}30- \\
O b s(\exp )\end{array}$ & $\begin{array}{l}35-38 \\
\operatorname{Obs}(\exp )\end{array}$ & $\begin{array}{l}\text { Total } \\
\text { Obs }(\exp )\end{array}$ & $S M R$ \\
\hline $\begin{array}{l}<10 \\
10- \\
15- \\
20- \\
25- \\
30-35\end{array}$ & $0(1 \cdot 15)$ & $\begin{array}{l}0(0 \cdot 18) \\
0(0.93)\end{array}$ & $\begin{array}{l}0(0.16) \\
1(0.19) \\
2(3.46)\end{array}$ & $\begin{array}{r}0(0.16) \\
2(0.41) \\
0(1.31) \\
13(8.22)\end{array}$ & $\begin{array}{r}0(0.09) \\
0(0.04) \\
2(1.34) \\
7(4 \cdot 00) \\
10(6.56)\end{array}$ & $\begin{array}{r}0(0.02) \\
1(0.21) \\
0(1.05) \\
2(3.17) \\
10(5.21) \\
7(1.76)\end{array}$ & $\begin{array}{l}0(0.00) \\
0(0.00) \\
0(0.01) \\
0(0.01) \\
2(1.03) \\
1(0.08)\end{array}$ & $\begin{array}{rr}0 & (1 \cdot 76) \\
4 & (1 \cdot 78) \\
4 & (7 \cdot 17) \\
22 & (15 \cdot 40) \\
22 & (12 \cdot 80) \\
8 & (1 \cdot 84)\end{array}$ & $\left.\begin{array}{c}0 \\
225 \\
56\end{array}\right\} 113+$ \\
\hline $\begin{array}{l}\text { Total } \\
\text { SMR }\end{array}$ & $\begin{array}{l}0(1 \cdot 15) \\
0\end{array}$ & $\begin{array}{l}0(1 \cdot 11) \\
0\end{array}$ & $\begin{array}{l}3(3 \cdot 81) \\
79\end{array}$ & $15(10 \cdot 10)$ & $\begin{array}{l}19(12.03) \\
158\end{array}$ & $\begin{array}{l}20(11 \cdot 42) \\
175^{\star}\end{array}$ & $265^{3(1 \cdot 13)}$ & $60(40 \cdot 75)$ & $147^{\star \star}$ \\
\hline
\end{tabular}

${ }^{\star} \mathrm{p}<0.05 ;{ }^{\star \star} \mathrm{p}<0.01$.

†Expected numbers less than 2 were combined.

Table 6 Observed and expected number of deaths in three groups of the copper miners

\begin{tabular}{|c|c|c|c|c|}
\hline \multirow[b]{2}{*}{ Groups of study } & \multicolumn{2}{|c|}{ All sites of cancer } & \multicolumn{2}{|c|}{ Lung Cancer } \\
\hline & $O b s(\exp )$ & $S M R$ & $O b s(\exp )$ & $S M R$ \\
\hline $\begin{array}{l}\text { All miners } \\
\text { Underground miners } \\
\text { Drilling miners }\end{array}$ & $\begin{array}{l}278(225 \cdot 16) \\
246(189 \cdot 23) \\
177(135 \cdot 27)\end{array}$ & $\begin{array}{l}123^{\star \star} \\
130^{\star \star} \\
131^{\star \star}\end{array}$ & $\begin{array}{l}60(40 \cdot 75) \\
57(33 \cdot 80) \\
48(24 \cdot 85)\end{array}$ & $\begin{array}{l}147^{\star \star} \\
169^{\star \star} \\
193^{\star \star}\end{array}$ \\
\hline
\end{tabular}

$\star{ }^{\star} \mathrm{p}<0 \cdot 01$. 
$(\mathrm{SMR}=169, \mathrm{p}<0.01)$ than among all miners $(S M R=147, p<0.05)$ with the highest risk of lung cancer for the drilling miners $(S M R=193$, $\mathrm{p}<0.01)$ (table 6).

\section{Discussion}

In our cohort, two follow up rates $(95.01 \%$ and $97 \cdot 00 \%$ respectively) were obtained from different methods. In the percentage method, the observed numbers of subjects at the end of the cohort (6734) was divided by the total number of subjects during the entire period of observation (7088) to give the follow up rate $(95.01 \%)$. This method is not ideal because the subjects who are lost and cannot be traced at the end of the cohort are not taken into account. These subjects have effectively contributed to some person-years at risk, which means that they have not strictly left the cohort. In the maximum person-year method, the follow up rate $(97.00 \%)$ was calculated as observed person-years (95 781) divided by maximum expected follow up person-years $(98743)$. The second method is therefore preferable.

The present study showed an excess of lung cancer in copper miners and the SMR was 147 taking the local population (Tongling city) as a reference group. Because the copper miners count for about $15 \%$ of the population in the reference population, the SMR calculated for lung cancer in copper miners might be underestimated. If the national male population was used as the standard, the SMR for lung cancer for the copper miners was 423 (observed $=60$, expected $=14 \cdot 2, \mathrm{p}<0.01$ ).

The magnitude of the SMR increased both with duration of exposure and with time since first exposure. Also, the substantial excess in deaths from lung cancer was strongly related to the degree of exposure as defined by work category. These findings indicate that mining of copper is a true occupational hazard.

In the early $1950 \mathrm{~s}$, the copper mines made a formal development and employed a large number of workers. At that time ore was obtained by a dry method of drilling. The ventilation of the mines was not improved, dust density was high, and the miners inhaled a great deal of the dust. After 1963 drilling was performed with a wet method and the ventilation in underground mines was improved. The dust concentration was relatively low. Such differences in work environments could explain the fact that there was a higher risk of lung cancer in the miners employed in the 1950s.

Wagoner et $a l^{1}$ found that the SMR of lung cancer in metal miners in the United States was 292. Radford et al ${ }^{6}$ reported that there was an excess of deaths from lung cancer (observed $=50$, expected $=12 \cdot 8$ ) in Swedish iron mine workers.
Fox et al ${ }^{2}$ also indicated that there was a twofold excess of lung cancer in tin miners. A high risk of mortality from lung cancer was reported in uranium miners exposed to radon daughters. ${ }^{3}{ }^{4}$ In these studies of metal miners, the increased risk of lung cancer was generally attributed to exposure of the miners to radon daughters. Although the biological effects of chronic exposure to radioactivity in the range of maximum permissible concentrations are unknown, it seems unlikely that the radiation exposure could account for the excess of deaths from lung cancer in the copper miners we investigated because (1) the concentration of radioactivity in the underground area of the mines was 1.29 (SD 0.55) $\times 10^{-11} \mathrm{Ci} / 1$, which is below the permission threshold of China $\left(3 \times 10^{-11} \mathrm{Ci} / 1\right)$; (2) the increase in the SMR of lung cancer in underground miners (see table 6), who were exposed to possible radiation, was mainly due to the drilling miners. After subtracting the observed and expected number of deaths from lung cancer for the drilling miners from those of the underground miners, the SMR of lung cancer was about 100 (observed $=9$, exposed $=8.95$ ).

Because the excess of deaths from lung cancer was highest among drilling miners and among miners employed in the 1950 s who were exposed to more dust, attention should be paid to the specific components of ore that have been suspected in carcinogenic activity in humans. As well as silica the ore in the mine contains iron, copper, manganese, arsenic, titanium, and sulphur in the order of diminishing quantities. ${ }^{9}$ Although arsenic is found to be a carcinogenic agent, the low concentration of arsenic in the copper ore $(0.061 \%)$ does not support a hypothesis that arsenic contributed to the excess of death from lung cancer in the copper miners. Some studies 1213 showed that silicosis and exposure to silica and iron might cause lung cancer. In our study, exposure to these two elements could not be ruled out as a potential cause of lung cancer.

Smoking is associated with increased risk of respiratory cancer. In our study, smoking habits could not be estimated retrospectively with sufficient accuracy to be taken into account. It is unlikely that our results were biased due to smoking behaviour because smoking is common among the general male population, and differences in smoking habits are likely to have caused only a minor degree of positive confounding ${ }^{14}$, furthermore, SMRs exceeding 150 (in our study, as discussed, the SMR of 147 is likely to be an underestimate) cannot be explained by increases in smoking alone. 1516 Nevertheless, we could not exclude a possible interaction between smoking and an occupational factor. The role of smoking as a confounding factor could be clarified by the case-control study we are currently carrying out on the copper miners. 
We are grateful to $\mathrm{Dr}$ Mengxuan $\mathrm{Hu}$ for helpful discussions during the course of this work and to Dr Alain-Jacques Valleron for his critical reviews of the manuscript.

Requests for reprints to: Dr Ruoling Chen, Department of Biostatistics, Anhui Medical University, Hefei, Anhui 230032, The People's Republic of China.

1 Wagoner JK, Miller RW, Lundin FE, Fraumeni JF, Haij ME. Unusual cancer mortality among a group of underground metal miners. N Eng f Med 1963;269:284-9.

2 Fox AJ, Goldblatt P, Kinlen LJ. A study of the mortality of Cornish tin miners. Br $\mathcal{F}$ Ind Med 1981;38:378-80.

3 Howe GR, Nair RC, Newcombe HB, Miller AB, Abbatt JD. Lung cancer mortality (1950-80) in relation to radon daughter exposure in a cohort of workers at the Eldorado Beaverloge uranium mine. I Natl Cancer Inst 1986;77: $357-60$.

4 Roscoe RJ, Steenland K, Halperin WE, Beaumont JJ, Waxweiler RJ. Lung cancer mortality among nonsmoking uranium miners exposed to radon daughters. $\mathcal{F} A M A 1989$; 262:629-33.

5 Hodgson JT, Jones RD. Mortality of a cohort of tin miners 1941-86. BrF Ind Med 1990;47:665-76.

6 Radford EP, Renard KGSC. Lung cancer in swedish iron miners exposed to low radon daughters. $N$ Engl f Med 1984; 310:1485-94.
7 Chen RL, Hu MX. A cohort study of cancer mortality in copper miners. In: Sakurai $\mathrm{H}$ et al, eds. Occupational Epidemiology. Amsterdam: Elsevier Science Publishers, 1990: $75-8$.

8 Ahlman K, Koskela RS, Kuikka P, Koponen M, Annanmäki M. Mortality among sulfide ore miners. Am $\mathcal{f}$ Ind Med 1991;19:603-17.

9 Xu BH, Gen AR, Chen GW, Shiao HD. Analysis and comparison of components of dust in five color metal mines. Hygiene Research 1988;17:10-3.

10 Chen RL, Hu MX. An analysis program for cohort studies of occupational cancer mortality. In: Gen GY, ed. Paper collection of the national symposium of chronic disease epidemiology and statistical analysis methods of investigated data. Tianjin, China: 1987:81-2.

11 Bailar JC, Ederer F. Significance factors for the ratio of a poisson variable to its expectation. Biometrics 1964;20:639-43.

12 Westerholm P, Ahlmark A, Maasing R, Segelbert I. Silicosis and lung cancer-a cohort study. In: Goldsmith DF, Winn DM, Shy CM, eds. Silica, silicosis, and cancer: controversy in occupational medecine. New York: Praeger, 1986:327-33.

13 Plamer WG, Scott WD. Lung cancer in ferrous foundry workers: A review. Am Ind Hyg Assoc f 1981;42:329-40.

14 Axelson O. Aspects on confounding in occupational health epidemiology. Scand 7 Work Environ Health 1978;485-9.

15 Steenland K, Beaumont J, Halperin W. Methods of control for smoking in occupational cohort mortality studies. Scand $\mathcal{F}$ Work Environ Health 1984;10:143-9.

16 Doll R. Occupational cancer: Problems in interpreting human evidence. Ann Occup Hyg 1984;28:291-305.

Accepted 27 July 1992

\section{Correspondence and editorials}

The British Journal of Industrial Medicine welcomes correspondence relating to any of the material appearing in the journal. Results from preliminary or small scale studies may also be published in the correspondence column if this seems appropriate. Letters should be not more than $\mathbf{5 0 0}$ words in length and contain a minimum of references. Table and figures should be kept to an absolute minimum. Letters are accepted on the understanding that they may be subject to editorial revision and shortening.

The journal now also publishes editorials which are normally specially commissioned. The Editor welcomes suggestions regarding suitable topics; those wishing to submit an editorial, however, should do so only after discussion with the Editor. 